\title{
LA PREVENCIÓN CONTRA EL FUEGO EN LA CONSTRUCCIÓN
}

\author{
(FIRE PREVENTION IN CONSTRUCTION SITES)
}

Andrés Calvo Barrios, Arquitecto Técnico

Servicio de Extinción del Ayuntamiento de Madrid ESPAÑA

Fecha de recepción: 14-I-93

\section{RESUMEN}

Original, documentado y profundo estudio sobre la incidencia de las Normas y Ordenanzas específicas en la Fase de Ejecución de Obras y sobre la técnica y métodos a aplicar en Obras de Edificación para prevenir y atajar los incendios en el proceso de producción.
SUMMARY

Original, documented and thorough study on the incidence of the specific Norms and Ordinances for the Phase of Execution of Works and on the techniques and methods to be applied in Construction Works in order to prevent and stop fires during the process of production.

\section{NECESIDAD}

El fuego es un elemento devastador cuando no se encuentra controlado. Surge de una manera imprevisible para quien lo sufre y, si no ha sido tenido en cuenta, sus consecuencias pueden ser muy trágicas y causar numerosas pérdidas, no sólo materiales sino humanas.

La falta de conocimiento de los orígenes del fuego, su desarrollo y modos de transmisión es un error que puede pagarse muy caro. Si en la vida cotidiana estamos acostumbrados a tratar con numerosos posibles focos de incendio y nos vemos rodeados de materiales combustibles en el desarrollo de una obra de edificación, estos focos se ven acrecentados y los combustibles los encontramos en situación más propensa para arder.

De ahí la necesidad de conocer a fondo todas las labores que se ejecutan en obra, su correcta realización y las precauciones necesarias para adoptar en cada una de ellas. No obstante, la impericia, accidente o el azar nos puede deparar un incendio, siendo entonces necesario controlar su desarrollo hasta su extinción. Por ello este factor también debe ser tenido en cuenta para prever que el desarrollo sea mínimo y disponer de los medios necesarios para atajarlo con prontitud.

Durante el desarrollo de una obra, existen fases en las cuales un fuego puede tener consecuencias irreparables, no sólo a nivel material sino humano, por ello la previsión de un posible incendio debe estar presente durante todas las fases de ejecución y desarrollo de la obra.

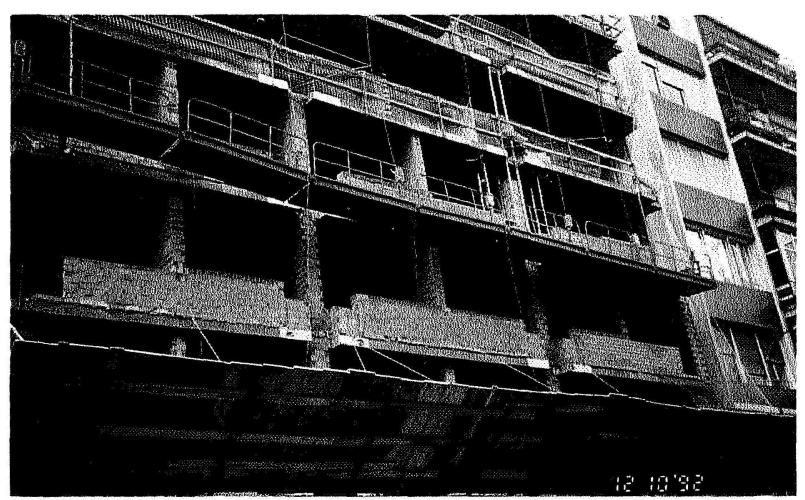

Pantallas, andamios y mallas. 


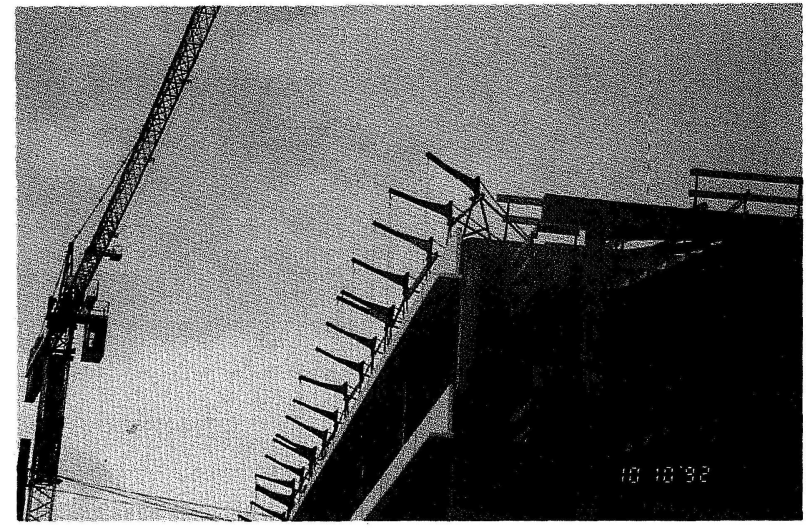

Voladizos

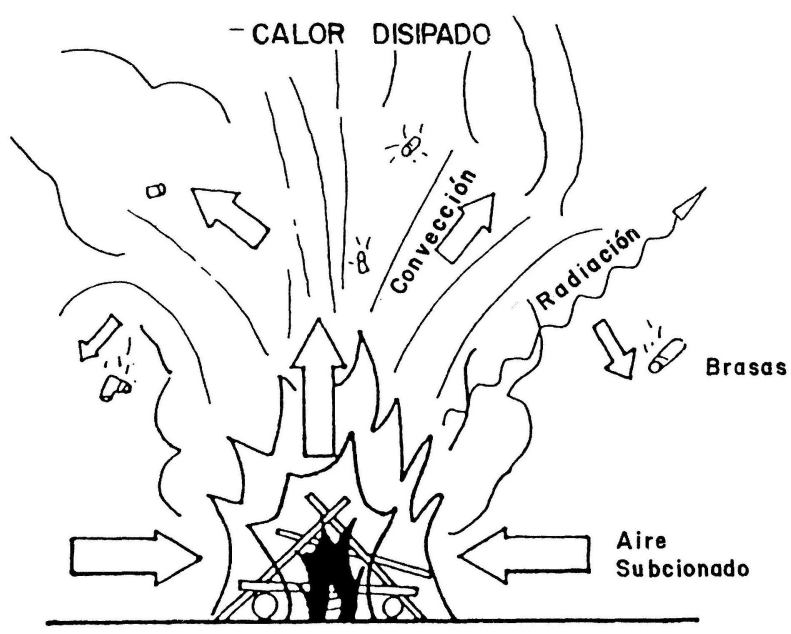

Fig. 1.-Fuego exterior.
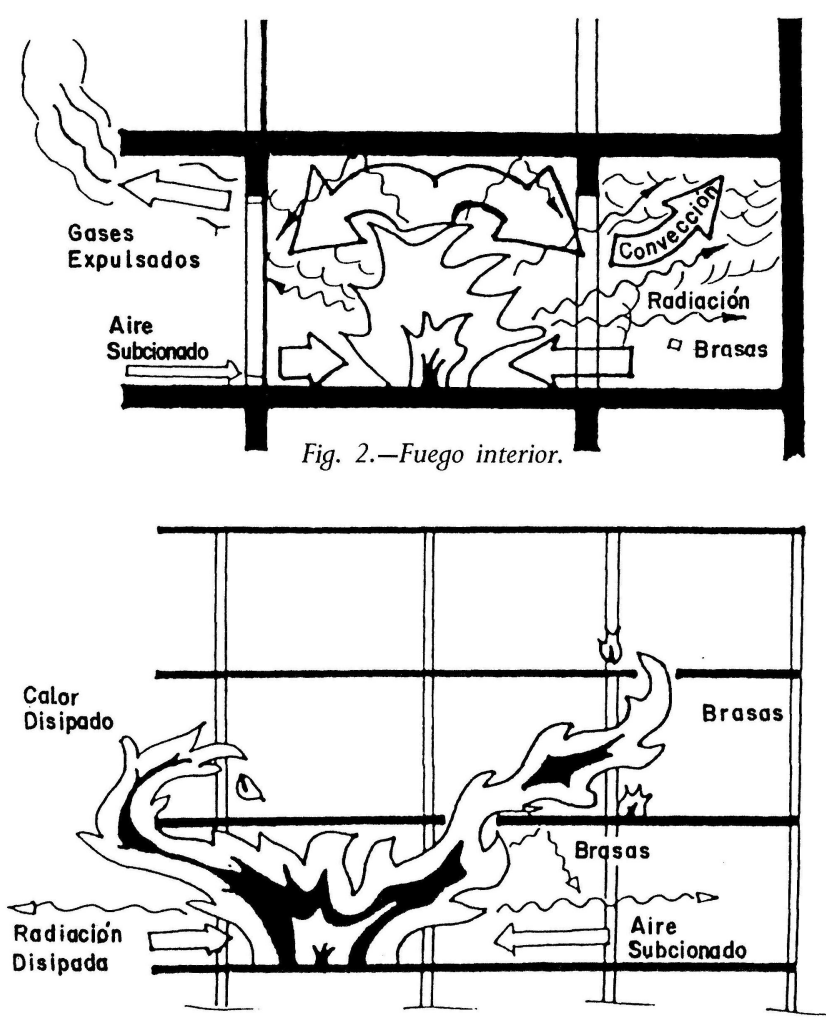

Fig. 3.-Fuego en obra.

\section{RIESGOS DE INCENDIOS DURANTE LA EJECUCIÓN Y REFORMA DE EDIFICIOS}

Los edificios durante su ejecución son tan propensos a la existencia de incendios como lo pueda ser uno ya ejecutado. En el caso de obras de reforma o reacondicionamiento el riesgo es algo mayor.

Los incendios no se descubren en una primera fase al existir menor número de ocupantes en los mismos y ser normal el no disponer de vigilancia durante las horas no laborables. Así disponen de una mayor facilidad para extenderse. Una vez iniciados no encuentran dificultades para su desarrollo dada la inexistencia de tabiques divisorios y puertas, existencia de huecos de obra en forjados y una carga de fuego elevada. Todo ello con almacén de obra, en especial productos peligrosos y de mayor riesgo potencial como disolventes, combustibles, gases comprimidos, etc., combinado con la carencia de medios adecuados de extinción y dificultades de accesibilidad.

Como resultado de estas circunstancias, la posibilidad de que el incendio pueda propagarse con mayor rapidez y genere grandes pérdidas, es elevada.

Con una adecuada planificación previa de la obra contemplando estos aspectos, podemos reducir los riesgos de siniestro, no olvidando en ningún momento las labores propias de obra que son potencialmente causa de ellos tomando las precauciones necesarias.

\section{CARACTERÍSTICAS PROPIAS DE LOS INCENDIOS DE OBRA}

Podemos diferenciar claramente entre un incendio en el exterior, en espacios diáfanos, y el siniestro en los interiores de edificaciones.

Los fuegos al exterior son en general de carácter mucho más lento al no existir elementos que faciliten su transmisión y siendo las corrientes de aire que generan poco favorables a su extensión. Así el sentido del aire fresco tiende hacia el interior del foco donde se consume parcialmente y se calienta ascendiendo con gran rapidez y disipando el calor en la atmósfera. Sólo en caso de ser arrastradas partículas incandescentes con volu- 
men y masa suficientes como para alcanzar de nuevo el suelo, todavía calientes, propagarán el fuego de modo indirecto. (Fig. 1).

En el interior de los edificios, las corrientes de aire caliente se extienden por los diversos recintos propiciándolos a la inflamación, recibiendo también el calor de radiación del foco que en el exterior se disipa puede dejar a los materiales en condiciones de que una brasa procedente de aquél produzca fácilmente un nuevo fuego. (Fig. 2).

En el caso de un edificio, durante su ejecución nos encontramos en un estado intermedio que, en una fase de obra avanzada, reúne las peores características de ambos tipos. El fuego tendrá gran aportación de aire y por tanto será más virulento y de rápido desarrollo, las corrientes de aire caliente encontrarán numerosos puntos del edificio donde no disiparse y poner su carga de brasas y teas que provocarán nuevos focos, avanzando fácilmente por las fachadas a medio terminar y huecos existentes en los forjados. Por otra parte, el calor radiante tampoco se disipa totalmente, favoreciendo la extensión en las zonas próximas. (Fig. 3).

\section{DESARROLLO DE UN FUEGO}

\section{PRINCIPIOS GENERALES}

Antes de nada debemos conocer qué es un fuego: El fuego es una reacción de oxidación en la cual un elemento combustible reacciona con un oxidante, en general el oxígeno del aire, con desprendimiento de energía, en forma de calor, gases calientes y luz. Este calor desprendido sirve para autoalimentar al fuego, facilitando su mantenimiento.

Cuando un combustible se quema, no lo hace directamente (salvo en contadas ocasiones) sino que previamente es preciso que la superficie del combustible sea calentada. Entonces comenzarán a desprenderse gases del mismo, aumentando su cantidad con el ascenso de la temperatura. Dependiendo del material y de la cantidad de oxígeno presente, estos gases se inflamarán a una temperatura determinada, desprendiendo calor que realimentará la producción de gases y continuará así el proceso.

Con lo dicho es fácil deducir el concepto del fuego manejado desde antaño y denominado triángulo del fuego

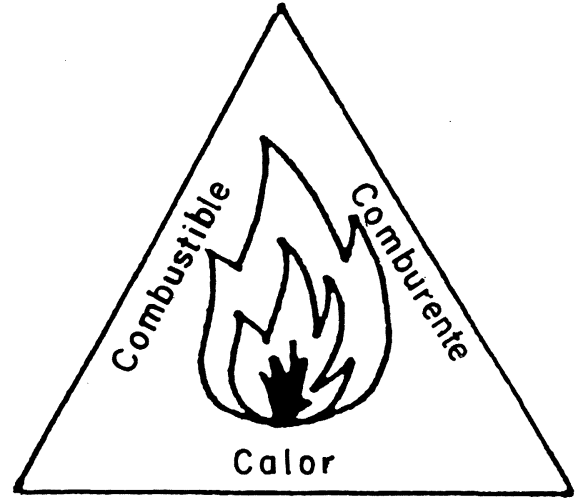

Fig. 4.-Triángulo del fuego.

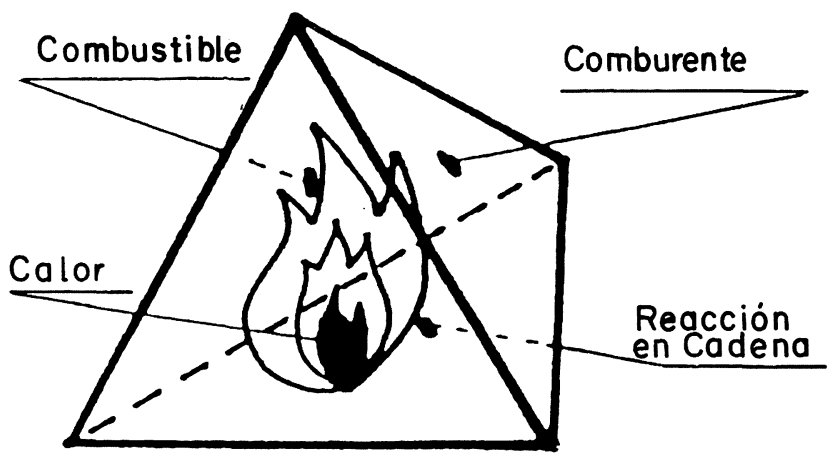

Fig. 5.-Tetraedro del fuego.

compuesto por combustible, oxígeno y calor. Si retiramos cualquiera de los tres elementos: combustible, sofocación o enfriamiento no podrá continuar el fuego. (Fig. 4).

Hay un cuarto elemento del fuego que se produce en la llama: la propia reacción química de combustión, que conforma el cuarto lado del denominado más recientemente tetraedro del fuego. Si impedimos esta reacción, cortamos el desarrollo del incendio. Los agentes extintores denominados halones y sus más recientes sustitutos actúan en esta fase impidiendo la combustión. (Fig. 5).

\section{EXTINCIÓN}

Con lo dicho se deducen los sistemas de extinción posibles de un incendio: retirada de combustible, retirada del oxígeno, enfriamiento y rotura de la reacción química de combustión. En general no se utiliza cada método por separado, sino que se combinan simultáneamente varios métodos. 


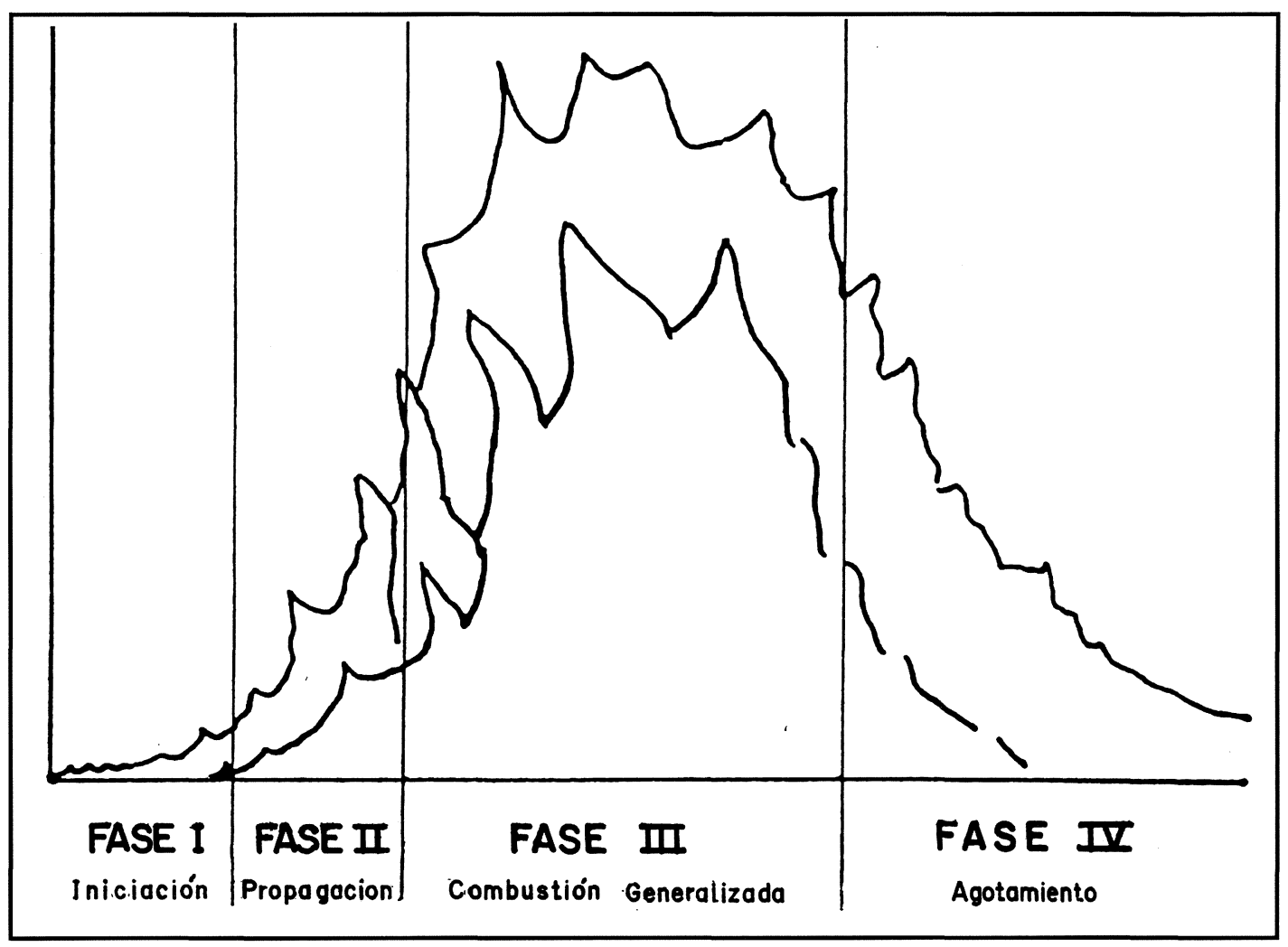

Fig. 6.-Fases de un incendio.

El agua: no sólo sirve para enfriar el foco al evaporarse y absorber calor. También es desplazado el oxígeno por el propio vapor y pudiéramos decir que retira el combustible al formar una película sobre y en el interior del mismo.

El Co: no sólo desplaza al oxígeno del espacio en que se dispara, también produce el enfriamiento del mismo e incluso el aislamiento del combustible (nieve).

Los polvos químicos: en general actúan sofocando el combustible, disponiendo según el tipo de polvo de la posibilidad de realizar un enfriamiento del mismo.

Los halones: no sólo actuán cortando la reacción química, también tienen una función de sofocación al desplazar el oxígeno del aire y un cierto grado de enfriamiento. Los sustitutos, actualmente en estudio y que estarán pronto en el mercado, actúan de manera similar.

Además hay que tener en cuenta que para cada tipo de fuego existe un agente extintor más apropiado, siendo inútiles algunos agentes en fuegos concretos e incluso peligrosos o contraproducentes.

\section{TRANSMISIÓN Y DESARROLLO}

El fuego se transmite por cuatro vías diferentes al igual que el calor: conducción, convención, radiación y contacto directo con la llama. Para evitar su propagación no basta con eliminar una o más de estas vías, hay que eliminarlas todas ellas. Como esto no es siempre posible, se pueden eliminar varias de ellas y atemperar las restantes, si por alguna causa es imposible eliminarlas.

De forma genérica, se encuentra admitido que el fuego tiene cuatro fases de desarrollo diferenciales:

I - Iniciación.

II - Propagación.

III - Combustión generalizada.

IV - Agotamiento.

En la fase de iniciación, es donde una pequeña fuente de energía calienta lo suficiente un elemento para que éste comience a consumirse, generando calor y autoalimentándose hasta que se produce el fuego, pudiendo haber transcurrido unos instantes o incluso muchos minutos. En ese momento comienza la segunda fase en la cual el fuego va extendiéndose y generando calor que 
recaliente los elementos próximos preparándolos para arder. Cuando estos elementos combustibles alcancen la temperatura adecuada, se inflamarán casi simultáneamente entrando en la tercera y más virulenta fase de combustión generalizada. Cuando se ha agotado prácticamente el oxígeno en la segunda fase, puede comenzar la combustión súbita al abrirse un hueco que lo proporcione, dado que todos los combustibles se encuentran muy calientes. A partir de este momento se consume la totalidad del combustible en un tiempo más o menos largo, hasta entrar en la fase cuarta de agotamiento. (Fig. 6).

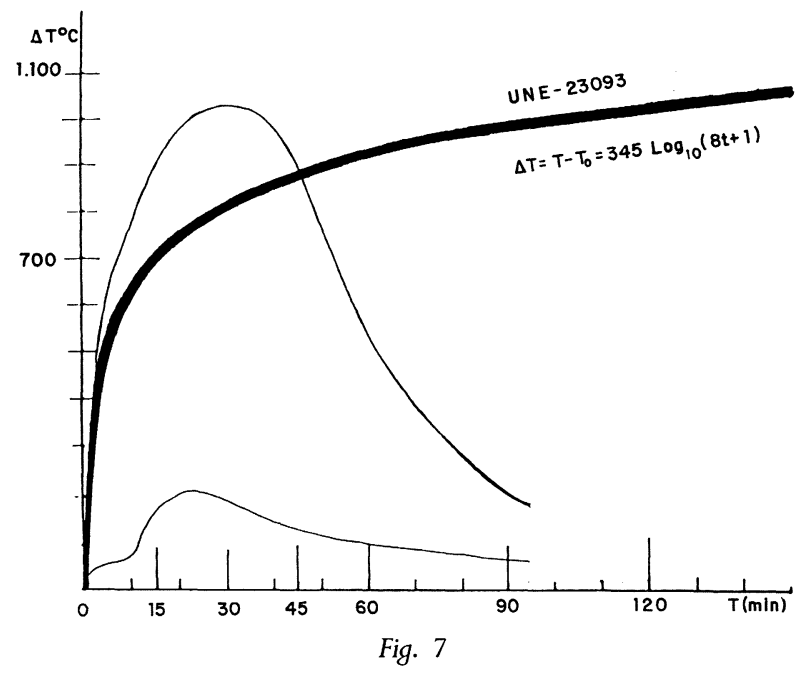

PROGRAMA TÉĆNICO NORMALIZADO. CURVAS DE FUEGO TIPO

La necesidad de establecer un procedimiento de ensayo sistemático normalizado, ante la gran diversidad de fuegos, diversos países adoptaron programas térmicos normalizados ajustados a curvas tiempo-temperatura que son en general bastante conservadoras respecto a los posibles incendios reales (discutible al no considerar la fase de enfriamiento). Presentan en general un desarrollo rápido de diez minutos y una ralentización a partir de $700{ }^{\circ} \mathrm{C}$ hasta alcanzar temperaturas próximas a los $1.000{ }^{\circ} \mathrm{C}$. (Fig. 7).

En España la Norma UNE-23.093-81 (ISO-834) corresponde a la ecuación:

$\triangle T=T-T_{0}=345 \log _{10}(8 t+1)$

$\mathrm{t}=$ tiempo en minutos.

$\mathrm{T}=$ temperatura en el horno en un instante $\mathrm{t}$.

$\mathrm{T}_{0}=$ temperatura inicial.

Presentan las objeciones de no contemplar la fase de enfriamiento; contemplar para ensayos tiempos muy superiores a los reales a altas temperaturas, y no contemplar la diferencia de temperatura en las zonas superiores e inferiores de los recintos que pueden superar los $500{ }^{\circ} \mathrm{C}$. Todos ellos aspectos que inciden fundamentalmente en el comportamiento de los materiales y en especial de las estructuras. 


\section{MOVIMIENTO DE LOS HUMOS}

En el interior de un recinto la mayor parte $(60 \%)$ de los gases y humos de combustión está constituido por aire arrastrado por corrientes de convención. En la parte superior se acumulan los gases y humos calientes a temperatura similara a la del foco, enfriándose a medida que descendemos y nos alejamos de éste. El nivel inferior de humos viene marcado por un estado de equilibrio entre los volúmenes del aire arrastrado y humos expulsados por los huecos de ventilación. Se establece un plano neutro de presiones sobre el cual la tendencia es la expulsión de gases por sobrepresión y bajo el mismo la admisión de aire fresco por depresión, situándose normalmente a unas alturas entre $1 \mathrm{~m}$ y $1,5 \mathrm{~m}$.

En caso de ventilación escasa el plano neutro desciende por debajo de los $0,5 \mathrm{~m}$ o menos, con un desarrollo de incendio más lento y con temperaturas bastante inferiores a las temperaturas críticas de los materiales. En este caso el mayor peligro lo supone la apertura de huecos. Dará aire fresco generando la rápida subida de la temperatura por combustión súbita generalizada (flash-over) y una explosión de los gases contenidos, pasando rápidamente a una situación menos ahogada.

El efecto chimenea consiste en las corrientes de aire producidas en el interior de un edificio (generalmente la caja de escalera) por la diferencia de temperatura entre el interior y exterior del edificio.

El aire interior es más caliente y tiende a ascender para salir por los huecos que se encuentran en la parte superior, tendiendo el aire frío a entrar por la parte inferior del edificio. Se diferencian dos zonas en todo él: una con sobrepresión y tendencia a la expulsión de aire por sus huecos y otra en depresión y con tendencia a la absorción de aire del exterior por los suyos. Este efecto se puede ver invertido en condiciones contrarias, fundamentalmente en verano.

Su importancia en un incendio es fundamental para su desarrollo, siendo ambos afectados por los vientos existentes.

La posición del plano neutro de presiones en el efecto chimenea es inversamente proporcional al cuadrado de las superficies de las aberturas y a la relación entre las temperaturas absolutas del aire, es decir:

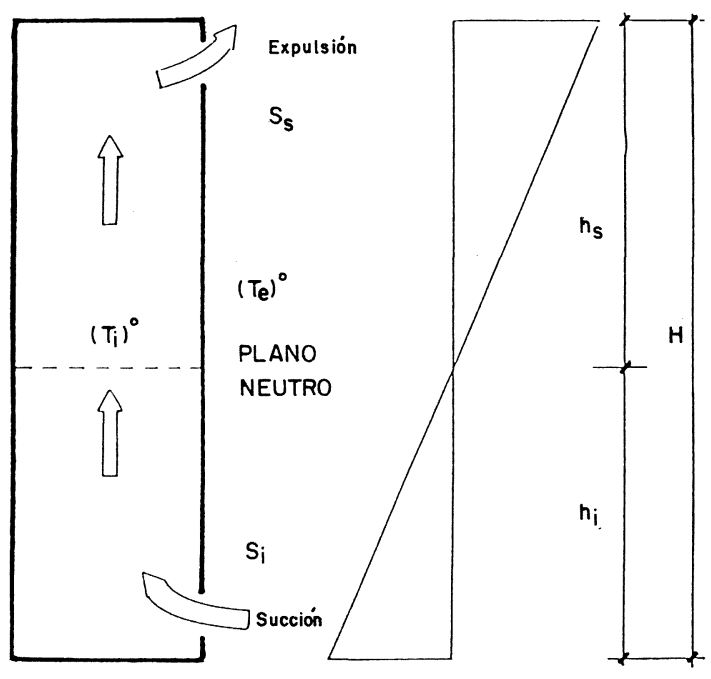

Fig. 8.-Efecto chimenea.

$$
\frac{h_{i}}{h_{s}}=\frac{S s^{2} T e}{S i^{2} T i}
$$

Por lo tanto si aumentamos la ventilación inferior, abriendo huecos, descenderá el plano neutro, y al contrario, si la disminuimos ascenderá este plano. (Fig. 9).

La influencia del viento es seria aumentando la cota en la zona de barlovento y disminuyendo en sotavento, con los consiguientes cambios en las zonas de absorción y expulsión de gases.

La existencia de sistemas de ventilación forzada cambia totalmente el movimiento, presiones y depresiones de los gases del edificio.

Todas estas circunstancias son de vital importancia en el desarrollo de un siniestro en edificios de altura. Por este motivo y a fin de hacer desaparecer el efecto chimenea en estos edificios, se exige en todas las normativas actuales de prevención de incendios, la compartimentación de las escaleras mediante vestíbulos de independencia que garanticen la estanquidad de las escaleras respecto de los diversos pisos y un posible fuego que se diera en éstos. Del mismo modo los conductos verticales de todo tipo: ventilación, patinillos, ascensores, etc., deben de reunir similares condiciones con una adecuada compartimentación.

Igualmente durante la ejecución de una obra el respetar y tener en cuenta estas circunstancias es fundamental para evitar la propagación de un incendio. Hay que 


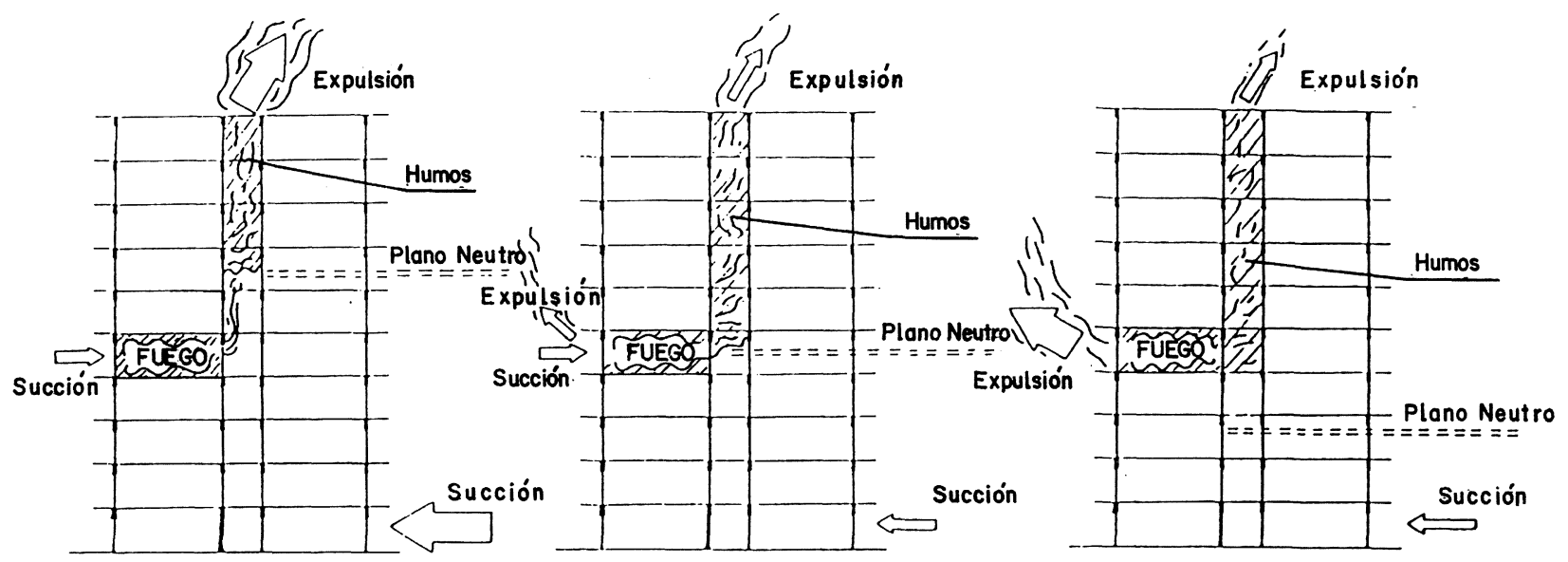

Fig. 9

tener en cuenta que a gases y humos calientes del fuego les acompañan brasas y partículas incandescentes que iniciarán nuevos focos y las propias llamas siguen el mismo recorrido. Se evitará en todo momento situar materiales combustibles almacenados en un camino previsible.

En las grandes superficies diáfanas, los humos se comportan de una manera especial. Se extienden recorriendo todo el techo, mezclándose con el aire fresco y enfriándose. Por ello descienden nuevamente e invaden con prontitud todo el volumen, reduciendo la visión a cero y extendiendo el siniestro. Esto se soluciona, parcialmente, situando ventilaciones naturales en el techo y dividiendo a nivel de techos el espacio para provocar la apertura más rápida de estos huecos, ya sea automáticamente o por rotura debido al calor. Con ello, conseguiremos dos funciones: facilitar el acceso a los bomberos y centrar el fuego en una zona concreta. (Fig. 10).
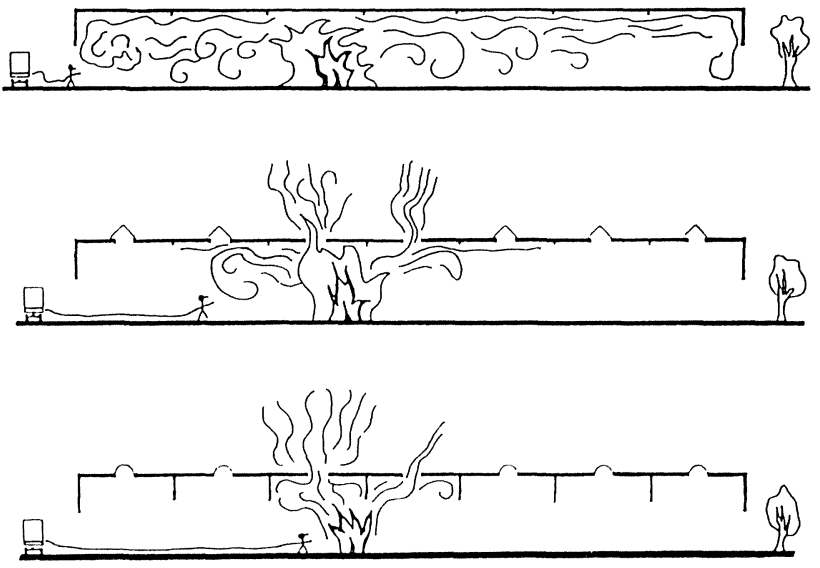

Fig. 10

\section{MEDIDAS DE PROTECCIÓN CONTRA INCENDIOS}

Aparte de las propias medidas de prevención contra incendios en las distintas labores y actividades de una obra, así como las previsibles instalaciones de protección contra incendios, hay que tener en cuenta otra serie de medidas de vital importancia.

Las vías de evacuación, tanto para los obreros como para los posibles ocupantes de los edificios en obra de reforma o reacondicionamiento, deben realizarse lo antes posible, manteniendo las existentes en perfecto estado de uso, sin riesgos añadidos de ningún tipo. Se mantendrá en ellas la compartimentación general del edificio y se evitará en todo momento que las mismas sirvan de almacenamiento, acceso o circulación de ningún tipo de materiales, salvo casos totalmente imprescindibles.

Cuando sea necesario desviar las rutas de salida, esto se realizará con posterioridad a la creación de otras nuevas igualmente seguras. Bajo ningún concepto se utilizarán materiales combustibles para la protección de estas vías provisionales. Los cambios de recorrido se realizarán fuera de horas de funcionamiento de las actividades, garantizándose en todo momento seguridad a ocupantes.

Es común en obras de reforma encontrar instalaciones contra incendio, como bocas de agua y columnas de secas que se debieran mantener en estado de uso. En caso de ser necesaria su demolición o cambio, es preferible hacerlo por fases y zonas, no dejando todo el edificio sin proteger y sustituyéndolas por otras nuevas o reconectándolas lo antes posible. 
Las basuras, así como los materiales de derribo, no deben acumularse en obra por ser en general una fuente de alimentación para los incendios. Conviene retirarlos diariamente o con mayor frecuencia. Realizar huecos en los forjados para evacuación de basuras, ya sea con conductos o sin ellos, es práctica arriesgada pues facilita enormemente la transmisión del fuego a su través.

Por tanto es preferible situar conductos y tolvas que los evacúen por el exterior.

El material almacenado en obra, de tipo combustible, se debe situar lejos de los huecos existentes en los forjados, escaleras o ascensores, para evitar la propagación por los mismos, tanto como productores de siniestro como para evitar ser alcanzados por un posible siniestro. Del mismo modo, no debe almacenarse junto a las fachadas y a ser posible se almacenará en plantas discontinuas o discontinuidad de su situación en cada planta.

En toda obra se reúnen normalmente diversas empresas a las que se asignan distintos trabajos, éstas deben supervisarse en todo momento por una persona encargada de coordinar a todas ellas en un mismo plan de protección. A ser posible éste se realizará por escrito para cada proyecto en particular.

Es difícil conseguir proteger estructuras contra el fuego durante la ejecución de una obra. No obstante resulta de gran importancia su protección, pudiéndose establecer un orden de ejecución que nos permita proteger la estructura conforme se va realizando. Una estructura afectada por el fuego durante la obra puede exigir su sustitución o incluso colapsar.

En este mismo sentido tenemos las estructuras de madera en obras de rehabilitación, siendo común el descubrirlas y dejarlas a merced del fuego. Los propietarios de los edificios pueden quedar maravillados por su belleza deseando mantener éstas parcialmente vistas después de la reforma, no comprendiendo el motivo por el cual estaban ocultas, siendo en gran medida la protección de la madera contra el fuego.

\section{INSTALACIONES DE PROTECCIÓN CONTRA INCENDIOS}

Salvo en las obras de reforma, donde podemos encontrar variedad de instalaciones de protección contra in- cendios, en una obra disponemos de medios más bien escasos. En general, dispondremos de medios de tipo manual siendo inexistentes las instalaciones fijas, ya sean de extinción como de prevención.

Con carácter general podemos encontrar tres instalaciones útiles en la obra:

- Mangueras de agua de riego: son usadas normalmente en todas las obras y pueden sernos útiles para sofocar un fuego incipiente. Debemos tener cuidado y no usarlas en fuego que no sean de tipo A o que presenten riesgos eléctricos.

Normalmente no reúnen las características apropiadas para su uso en la extinción de un siniestro. En el caso de obras de reforma podemos disponer de bocas de agua contra incendio equipadas. Es conveniente mantenelas en uso, siendo precisa la realización de ligeras modificaciones en la red durante el transcurso de la obra, a fin de que dispongan de presión y caudal en todo momento. Caso de no ser posible podemos realizar una instalación hasta la vía pública o zonas de acceso y dotarla de unas bocas siamesas con racores tipo Barcelona, convirtiéndolas en "Columnas secas". Por esta instalación podrán conectar los servicios de bomberos a su llegada, disponiendo de bocas de agua en todo el edificio y ahorrándose el tiempo necesario para realizar el tendido de la instalación.

En la ejecución de obras que se vaya a disponer de estas bocas, es conveniente instalarlas, aún de modo pruvisional, conforme se ejecuta la obra.

Lo anteriormente dicho es igualmente válido para la instalación de "Columnas secas".

- Extintores portátiles: podemos aprovechar los existentes en obras de reforma, cuidando que se encuentren en estado de uso. En obras de nueva ejecución se adquirirán para la misma.

Como precaucaciones importantes señalaremos cuatro:

1. Q Que el tipo de agente extintor sea el adecuado.

2. Que se encuentren visibles.

3. En estado de uso.

4. Informar a los trabajadores de su funcionamiento, donde no deben utilizarse y los riesgos del uso indebido. 


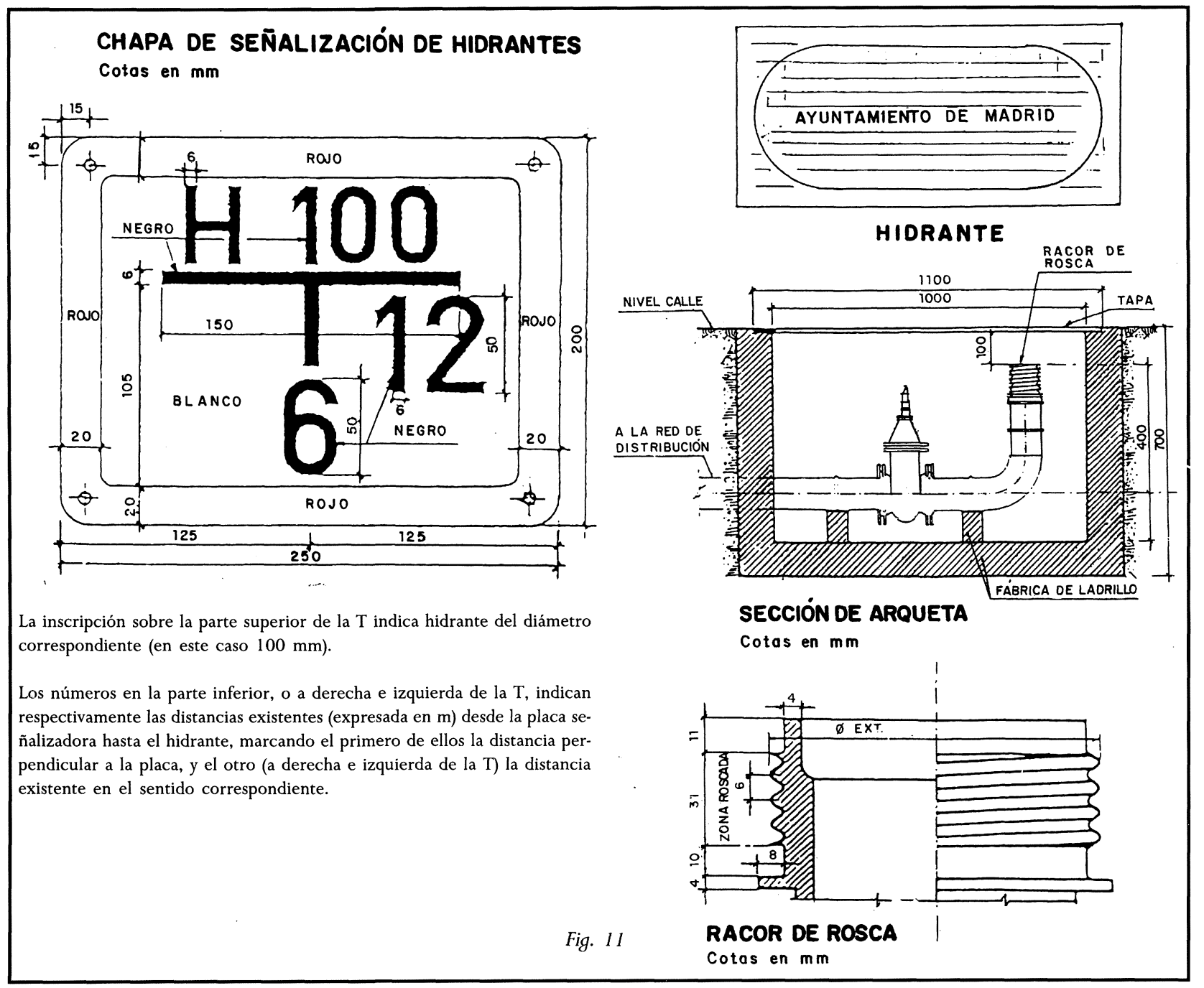

- Hidrantes de bomberos y bocas de riego públicas: es de enorme importancia conocer su situación en las proximidades, en especial de los primeros ya que garantizan a los servicios contra incendios el agua necesaria para la extinción. Cuando éstos lleguen se les debe informar de su situación. (Fig. 11).

Otros útiles de obra que pueden servir para la extinción de incendios en la misma son los cubos, rastrillos, palas, arena, maquinaria de movimiento de tierras, bidones y depósitos de agua, etcétera.

Así mismo, y si el tipo de obra lo aconseja, se puede disponer de personal especializado y dotado de material adecuado para la actuación en caso de incendio. Este material consiste como mínimo en casco, botas, guantes y traje no inflamable, mandil, mascarilla y cinturón de seguridad, a fin de poderse aproximar a un fuego aún incipiente y hacer uso de extintores y mangueras.
Este mismo personal, o parte de él, debe ser el encargado de realizar la vigilancia y control de la seguridad contra incendios en la obra. Apagarán los fuegos realizados en la obra o comprobarán que se encuentran sofocados; controlarán las instalaciones de alumbrado para que no puedan generar un incendio, así como la situación de calefactores, secadores y zonas donde se hayan realizado operaciones de corte con radial, soldadura, etcétera.

Especialmente en obras de reforma nos podemos encontrar con otras instalaciones, como son las de extinción automática de incendios o de detección que es muy conveniente mantener en uso. Cuando éstas vayan a ser instaladas deben ser puestas en estado de uso lo más pronto posible. 